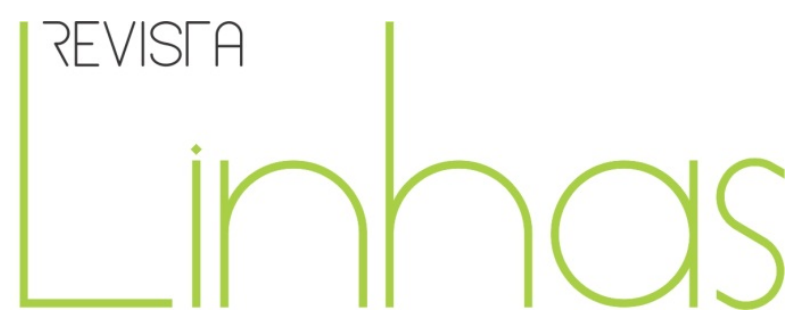

\title{
A expansão do atendimento na rede pública municipal de educação infantil de Florianópolis: estratégias dos governos municipais (1976 - 2011)
}

\begin{abstract}
Resumo
Com o presente trabalho, analisamos os dados de expansão do atendimento da Rede Pública Municipal de Educação Infantil de Florianópolis (RMEI), apontando estratégias dos governos municipais em relação à expansão de atendimento das crianças de zero a seis anos. Neste sentido, recorremos a alguns autores para o diálogo, que, a partir de informações encontradas nos documentos como os planos de governo e os relatórios das gestões, mostram o atrelamento do município às políticas nacionais. Identificamos a primeira onda expansionista da pré-escola, caracterizada pelo atendimento das populações de baixa renda. Posteriormente, visualizamos uma nova onda expansionista, não mais atrelada aos programas de caráter compensatório, mas apresentando como opção de atendimento por meio de convênios com instituições filantrópicas e/ou comunitárias. Após o Regime Militar, verificamos uma preocupação com o caráter educativo do atendimento às crianças, iniciativas democráticas como a eleição de diretores, conselhos escolares, assim como também ameaças a estes mesmos mecanismos. Após a LDB de 1996, surgem ações a respeito do Sistema Municipal de Educação e aparecem as primeiras resoluções sobre Educação Infantil no município. Estratégias como "uma vaga a mais pelo Conselho Tutelar", grupos mistos, parcialização do atendimento, preenchimento das vagas em aberto, e outras, como "creche ampliada", municipalização, extinção dos NACs (creches domiciliares) e Termo de Ajuste de Conduta (TAC) junto ao Ministério Público de Santa Catarina, vão fazendo parte desta história.
\end{abstract}

Palavras-chave: Educação Infantil; Expansão do atendimento; Estratégias de expansão.

\section{Para citar este artigo:}

OESTREICH, Marlise. A expansão do atendimento na rede pública municipal de educação infantil de Florianópolis: estratégias dos governos municipais (1976 - 2011). Revista Linhas, Florianópolis, v. 15, n. 28, p. 370-399, jan./jun. 2014.

DOI: $10.5965 / 1984723815282014370$

http://dx.doi.org/10.5965/1984723815282014370 


\title{
The Expansion of The Service In The Municipal Public Network Of Primary Education In Florianópolis: City Hall's Strategies (1976-2011)
}

\begin{abstract}
This work presents the data collected from the service expansion for the municipal public network of Primary Education in Florianópolis, pointing at strategies of the city hall in relation to the expansion of the service to children from 0 through 6 years of age. Therefore, we brought some authors to the debate, in which we realized the bond of the municipality to the national policies, found in the documents, as the government plans and management reports. We have identified the first expansionist wave of pre-school, characterized by the services to the low income population. Later, we visualized a new expansionist wave, not bond to the compensatory programs anymore, but presenting as a service option accords with philanthropic and/or communitarian institutions. Following the military dictatorship, we found not only a concern with the educational aspect of the service to the children, democratic initiatives, as principals' elections, school councils; but also threats to these democratic mechanisms. After LDB of 1996 there were actions regarding the Education Municipal System, the first resolutions of the primary school in the municipality appears. Strategies as: "one more vacancy for Tutelary/Custodial Council"; mixed groups; section of the service; occupation of the vacant places; and others, as the "amplified nursery school"; the municipalization; the extinction of the "home nurseries" -- NAC; and the Term of Conduct Engagement -- Termo de Ajuste de Conduta - TAC - by the Public Ministry of Santa Catarina, are part of that history.
\end{abstract}

Keywords: Primary Education; Expansion of the service; Strategies of expansion. 


\section{Introdução}

Apresentamos, neste estudo, as estratégias que foram e vêm sendo utilizadas pelos governos municipais ao longo dos anos, objetivando a expansão do atendimento da Educação Infantil, ou seja, o cumprimento do direito da criança de zero a seis anos, conforme preconiza a Constituição Federal de 1988. Apresentamos dados de atendimento desde 1976, quando se inicia no município o atendimento da pré-escola, bem como alguns indicativos nos documentos levantados que nos permitem chegar aos dias atuais. Desde o início do atendimento - 1976 -, verificamos que Florianópolis seguiu a orientação do atendimento à população de baixa renda, conforme a política educacional da época. Após a queda do Regime Militar, em 1986, legitimou-se a primeira eleição para prefeitos das capitais brasileiras, da qual saiu eleito Edson Andrino. Os ventos democráticos sopraram na capital catarinense, graças aos quais foi aprovada a lei de eleição para diretores e dos conselhos escolares. Constatamos, nos documentos, a preocupação com a questão do acesso à educação, assim como com a qualidade da educação pública, que procurou ampliar a concepção da educação de crianças. À de Andrino, segue-se a gestão de Amin/Bulcão (1989-1992), época em que o País vive uma nova onda expansionista. Se antes se aderia a programas de caráter compensatório, a opção agora eram os convênios com instituições de caráter filantrópico ou comunitário. Este aspecto pode ser igualmente visualizado na próxima gestão da Frente Popular (1993-1996), que aderiu à modalidade do zoneamento, conforme a rede estadual já vinha adotando em relação ao ensino fundamental. Esta gestão foi caracterizada por aspectos democráticos, estendendo a eleição de diretores a todas as instituições educativas da rede municipal, aos conselhos de escola, além do Movimento de Reorientação Curricular, cujo objetivo foi construir coletivamente a proposta curricular do município. Em 1997, assume a prefeita Ângela Amin, que adotou a perspectiva da meritocracia, cujos princípios se encontravam alinhavados com os da ideologia neoliberal. Por outro lado, nos encontramos no contexto pós-LDB de 1996, quando foram desencadeadas questões como a do Sistema Municipal de Educação, cuja lei foi aprovada somente em 2007. Em 1999, surgiu a primeira resolução de Educação Infantil do município. Seu governo seguiu por duas gestões consecutivas, e adotou as seguintes estratégias de expansão: uma vaga 
a mais do Conselho Tutelar, turmas com crianças de diferentes idades, parcialização do atendimento e preenchimento das vagas ociosas. Caracterizou-se, ainda, pela tentativa de retirada da eleição de diretores, provocando mobilização tanto dos trabalhadores da Educação quanto da sociedade civil. Os movimentos conseguiram preservar o processo eleitoral. O governo de Dário Berger, à frente da administração da capital catarinense por dois mandatos consecutivos (o último, concluído em 2012), previa a ampliação e qualificação da Educação Infantil, procurando modernizá-la, com ênfase nas pessoas. Para a expansão do atendimento, utilizou como estratégias o redimensionamento dos agrupamentos de crianças, investindo na ampliação das salas de atividades nas instituições que dispusessem de espaço físico, a que denominamos de "creche ampliada". No seu governo, foi celebrado o primeiro Termo de Ajuste de Conduta (2007) - TAC - junto ao Ministério Público. Além disto, extinguiu os NACs (Núcleos de Atendimento às Crianças - creches domiciliares) e municipalizou as creches estaduais, além de algumas construções de instituições com recursos federais.

\section{A rede municipal de educação infantil de Florianópolis}

Até o primeiro semestre de 2011, a Rede Municipal de Educação Infantil - RMEI contava com 81 instituições, sendo 49 creches e 32 núcleos de Educação Infantil (NEIs), totalizando 10.720 crianças atendidas. Além deste atendimento ofertado pela RMEI, há também o realizado pelos convênios, totalizando 21 instituições que atendiam a 2.088 crianças na ocasião.

Receberam a denominação de creche as instituições para crianças de quatro meses a cinco anos de idade, que atendiam em período integral, das 7 hoo às 19hoo. Já os NEls são instituições destinadas a crianças entre três e cinco anos de idade, cujo atendimento se dá em período parcial, num horário compreendido no turno matutino das 7 hoo às 13 hoo ou, no período vespertino, das 13 hoo às 19hoo. No entanto, cabe salientar que atualmente estas concepções - creches e NEls - vêm sofrendo alterações no aspecto atendimento, que é o critério da necessidade da comunidade atendida. Isto significa dizer que há atualmente NEls que atendem em horário e faixa etária antes destinados somente 
a creches. Até agosto de 2011, dos $32 \mathrm{NEIs}$ da RMEl, sete funcionavam com atendimento integral para todos os grupos etários; seis possuíam alguns grupos integrais e outros, parciais.

A RMEl de Florianópolis teve início em 1976, quando foram implantados, em caráter experimental, os NEls. Os primeiros foram estabelecidos nas comunidades da Coloninha/Estreito (NEI Coloninha), do Ribeirão da Ilha (NEI Ribeirão da Ilha) e de São João do Rio Vermelho (NEI Rio Vermelho). Estas comunidades foram escolhidas para atender diretamente "à população de baixa renda que vive no interior da ilha e na periferia da cidade" (FLORIANÓPOLIS, 1983, p. 72). Seu objetivo consistia em:

[...] suprir as deficiências do meio, oferecendo às crianças carentes as condições desejáveis para um desenvolvimento social e cognitivo, procurando minimizar os problemas das crianças cujas mães trabalham fora do lar e facilitar o ingresso do aluno no ensino regular. (FLORIANÓPOLIS, 1983, p. 72)

O NEl Coloninha passou a ser denominado, em 1977, Creche Professora Maria Barreiros. Era "uma nova modalidade de atendimento pré-escolar, pois, contemplando a criança de 0 a 6 anos (compreendido dos 3 meses aos 6 anos), também vai contemplar uma sistemática diferenciada para seu funcionamento" (OSTETTO, 2000. p. 68). Posteriormente, segundo a mesma autora, em 1979, foi construído o prédio próprio da Creche Professora Maria Barreiros, onde, conforme os relatos das professoras, foi efetivado o atendimento a crianças menores. Ainda neste mesmo ano foi definida a estrutura da prefeitura de Florianópolis.

Os dados sobre o número de matrículas na RMEI, que demonstram a expansão do atendimento feito pela rede pública municipal de Florianópolis de 1976 a 1979, são mostrados na tabela 1 .

Tabela 1 - Dados de matrícula da RMEI - 1976 a 1979

\begin{tabular}{c|c|c|c}
\hline 1976 & 1977 & 1978 & 1979 \\
\hline 92 & 150 & 166 & 463 \\
\hline
\end{tabular}

Fonte: OSTETTO (2000, p. 105) 
Verificamos, pelos dados, que de 1976 a 1979 surgiram 371 novas vagas, representando um crescimento de 403,26\%. Destaca-se um salto maior do ano de 1978 para o ano de 1979, quando o número de crianças atendidas passou de 166 para 463, significando 297 novas vagas, que perfizeram, unicamente neste período, um crescimento na ordem de $178,92 \%$.

Em 1979, Francisco de Assis Cordeiro assumiu a prefeitura (1979-1983). Neste período, o Ministério da Educação, Cultura e Desporto - MEC -, por meio de suas orientações, lançou uma onda de expansão na educação pré-escolar. Esta modalidade uma novidade pré-escolar no município - esteve em consonância com a política educacional do governo federal, centrando o atendimento na população de baixa renda. No seminário sobre Política e Planejamento da Educação e Cultura, realizado em julho de 1979 em Brasília, ficou estabelecido que um dos seus objetivos seria:

[...] formular e implantar a política global integrada para a infância como medida corretiva parcial aos efeitos das desigualdades de distribuição de renda, e preventiva, enquanto se procura eliminar os fatores determinantes da pobreza absoluta. (FLORIANÓPOLIS, 1983, p. 72)

Nesta direção, segundo Waltrick (2008), os efeitos foram igualmente sentidos no cenário local, tornando-se meta prioritária da administração municipal:

A Prefeitura Municipal de Florianópolis, por atender, na área educacional, predominantemente, à zona rural e periferias urbanas, atinge a clientela mais carente socioeconomicamente no Município. Por isso, procura dar ênfase aos programas de Alimentação e Nutrição, de Educação para a Saúde, de Assistência médico-odontológica, de integração Escola/Comunidade, de expansão do ensino pré-escolar. (FLORIANÓPOLIS, 1983, p. 72)

A análise dessa autora indica a permanência da orientação a respeito da expansão através das alternativas de baixo custo:

[...] a expansão priorizava as alternativas de baixo custo, incentivando-se as formas não convencionais de atendimento. Em que pese o acesso de um contingente de crianças vindas das camadas populares à educação pré-escolar, na verdade, a propalada democratização no acesso assumia 
uma dimensão meramente quantitativa. A qualidade ainda estava longe de ser resolvida. (FLORIANÓPOLIS, 1983, p. 73)

Dentre as justificativas para a inclusão do projeto, encontramos:

[...] o fato de haver, no interior da ilha (zona rural) e continental (zona marginal) da cidade, clientela carente economicamente, onde as crianças sofrem geralmente de subnutrição, de falta de cuidados de saúde e de carências de estímulos ao desenvolvimento normal e equilibrado de suas funções cerebrais, de sua afetividade e motricidade, repercutindo mais tarde na idade escolar ( 6 anos e 6 meses/7 anos) em dificuldades de aprendizagem e integração social. (FLORIANÓPOLIS, 1983, p. 28)

Assim, de modo geral, o Plano de Ação 1980-1983 citava o período integral (semiinternato) para as crianças do berçário e do maternal, estando condicionado "à mãe que trabalha fora de casa e de que a renda da família não ultrapasse três salários mínimos" (FLORIANÓPOLIS, 1983, p. 28). Já o atendimento de meio-período destinava-se às demais crianças.

Além disto, localizamos, no Plano de Ação 1980-1983, as ações para a expansão do atendimento:

- Implantação de núcleos de Educação Infantil nas localidades de Pantanal e Armação, através do Plano de Aplicação dos Recursos Orçamentários do SEPS/MEC (Secretaria do Ensino de Primeiro e Segundo Graus do Ministério da Educação e Cultura) - 1980/1981.

- Implantação de creches em Saco Grande, Costeira do Pirajubaé e centro, através de convênio entre Prefeitura Municipal e BIRD.

- Identificação das áreas populacionais com clientela carente suficiente para a implantação de pré-escolar.

- Definição de implantação de outros núcleos e creches nas áreas identificadas. (FLORIANÓPOLIS, 1983, p. 73)

Na tabela 2, apresentamos os dados das matrículas da RMEl entre 1980 e 1985.

Tabela 2 - Dados de matrícula da RMEI - 1980 a 1985

\begin{tabular}{l|c|c|c|c|c}
\hline 1980 & 1981 & 1982 & 1983 & 1984 & 1985 \\
\hline 530 & 581 & 923 & 1.612 & 1.967 & 1.989 \\
\hline
\end{tabular}

Fonte: OSTETTO (2000, p.105) 
Verificamos que, de 1981 para 1982, foram criadas 342 vagas na Educação Infantil, representando 58,86\% de crescimento; considerando o ano de 1982 a 1983, foram acrescentadas 689 novas vagas, totalizando $74,65 \%$ de aumento no atendimento. Estes dados revelam um aumento significativo entre os anos 1980 e 1985, criando-se 1.459 vagas, totalizando $275,28 \%$ de aumento. Somente no período de 1980 a 1983 são 1.082 novas vagas, o que correspondeu ao período de maior aumento, totalizando $204,15 \%$ exclusivamente nestes três anos.

Em 1986, nas primeiras eleições diretas para prefeito de capitais no nosso país, elegeu-se, na cidade de Florianópolis, Edison Andrino. Em sua gestão, foi criada a Secretaria Municipal de Educação e o Departamento de Educação Pré-escolar, além de oficializar as eleições de diretores nas escolas e criar a lei dos conselhos de escola.

Tendo por base o seu Plano de Ação - triênio 1986-1988, encontramos cinco propostas básicas: “1) Nenhuma criança fora da escola; 2) Recuperando a qualidade da Escola Pública; 3) Lutando contra o analfabetismo; 4) Atendimento ao Pré-escolar, e 5) Atendimento ao menor desassistido" (FLORIANÓPOLIS, 1986, p. 1).

Novamente, no Plano de Ação 1986-1988, consta um anteprojeto de expansão e ampliação da rede municipal de educação pré-escolar, cujo objetivo era "atender satisfatoriamente as crianças de nível socioeconômico baixo, residentes no município de Florianópolis" (FLORIANÓPOLIS, 1986, p. 176), apresentando como justificativas:

\footnotetext{
- Pelo fato de haver, no interior da ilha e zona continental da cidade, clientela carente economicamente, onde geralmente as crianças sofrem de subnutrição, de falta de cuidados de saúde e de carência de estímulos ao desenvolvimento normal e equilibrado.
}

- Pelo grande número de crianças que estão aguardando vagas para frequentar creches e NEls.

- Devido à já significativa presença da mulher fora do lar buscando recursos para a manutenção financeira da família (FLORIANÓPOLIS, 1986, p. 176).

Para alcançar estes objetivos, foi prevista a construção de mais creches em Santo Antônio de Lisboa, Carianos e Saco Grande II, e dos NEls localizados em Coqueiros, 
Jurerê, Ponta das Canas, Barra da Lagoa, Sambaqui, Morro do Céu, Tapera e Retiro da Lagoa (FLORIANÓPOLIS 1986, p. 176, 177, 178).

Com relação à síntese das propostas da SME, destacam-se em seu Plano de Ação de 1986-1988: a garantia de ensino público e gratuito na faixa de o a 16 anos e a garantia de matrícula a todas as crianças que procurem vagas, através da expansão e manutenção da RME (FLORIANÓPOLIS, 1986, p. 237).

De acordo com Waltrick (2008), nesse plano houve uma preocupação com o caráter pedagógico, o planejamento, a intencionalidade do trabalho nas instituições de Educação Infantil, mas não necessariamente com a expansão:

A prioridade dada ao atendimento pré-escolar se concretizará na contramão das orientações implementadas pelas administrações anteriores. Conforme já mencionamos, se na primeira metade da década de 1980 observamos um crescimento significativo nas taxas de atendimento, sobretudo via Projeto Casulo, na segunda metade da década verificaremos um movimento diferente há uma retenção na expansão e uma preocupação com o caráter pedagógico do trabalho desenvolvido nas unidades, com o planejamento e a intencionalidade pedagógica orientadora do mesmo [...]. (WALTRICK, 2008, p. 91)

Em outro documento, intitulado Relatório de Desenvolvimento da Política Educacional do município no período 1986/88, encontramos dados sobre o crescimento da matrícula durante esta gestão:

O número de alunos matriculados no pré-escolar em 1985 teve um acréscimo de 1,12\% em relação a 1984. Em 1986 o acréscimo da matrícula foi de 1,10\%; em 1987 apresentou um decréscimo de 10,5\%, contando com um aumento, em 1988, de $21,8 \%$ em relação a 1987 . A diferença percentual do número de matrículas no período $84 / 88$ na pré-escola apresentou um acréscimo de $12,55 \%$, significando mais 247 alunos. (FLORIANÓPOLIS, 1988, p. 7)

Apresentamos a tabela 3 com as matrículas na Educação Infantil entre os anos de 1985 e 1988 em Florianópolis.

Tabela 3 - Dados de matrícula da RMEI - 1985 a 1988

\begin{tabular}{l|c|c|c|c}
\hline & 1985 & 1986 & 1987 & 1988 \\
\hline Crianças & 1.989 & 2.080 & 2.098 & 2.214 \\
\hline Creches e NEIs & 32 & 35 & 36 & 37 \\
\hline
\end{tabular}

Fonte: OSTETTO (2000, p. 105) 
Assim, verificamos que do ano de 1986 para o ano de 1987 foram criadas somente 18 vagas, ao passo que entre 1987 e 1988 foram criadas 116 vagas, o que representou o baixo percentual de $6,44 \%$.

Este baixo índice explica a tentativa de ampliar a concepção de educação das crianças:

A orientação pedagógica da educação pré-escolar procurava, então, após a primeira "onda" expansionista, resultante das orientações políticas nacionais e locais, produzir uma "virada", em termos da recuperação da qualidade da educação pré-escolar, do afastamento de concepções assistencialistas, valorizando seu caráter educativo. (WALTRICK, 2008, p. 100)

Nos anos de 1989 a 1992, então na gestão Amin/Bulcão, observou-se, de acordo com a autora citada, uma nova "onda de expansão pré-escolar":

Um dos principais aspectos que observamos no que diz respeito à estrutura e à gestão dessa nova administração municipal refere-se a uma nova "onda expansionista", agora não mais por adesão aos programas de caráter compensatório nacionais, como vimos nos anos iniciais da rede, mas pela opção de conveniamento com instituições/entidades de caráter filantrópico e comunitário. (WALTRICK, 2008, p. 100)

Visualizamos no Relatório de Gestão - 1989/1992 - que o crescimento da pré-escola indicava 63,10\%, com taxas de crescimento assim distribuídas: “[...] o atendimento nos Núcleos de Educação Infantil, crianças na faixa etária de 3 a 6 anos, tendo um índice de 99,22\% [...] e o crescimento de matrículas nas creches (atendimento de o a 6 anos) na ordem de 22,64\%" (FLORIANÓPOLIS, 1992, p. 6).

Outro elemento encontrado diz respeito à importância de sua política de atendimento expansionista ao atendimento do pré-escolar:

[...] não somente por apresentar os maiores índices de crescimento nos 5 anos em estudo, mas também por ser a área de menor atendimento pela esfera administrativa municipal, atendendo, atualmente, somente $6,31 \%$ da demanda municipal. Contudo, o percentual de atendimento por rede, a matrícula de pré-escolar, em 1990, apresentou os seguintes indicadores: 1,02\% Federal, 17,02\% Estadual, 16,59\% Municipal e 65,37\% particular. [...] O atendimento ao pré-escolar deverá ter uma média de crescimento de 12,81\% ao ano. (FLORIANÓPOLIS, 1992, p. 6-7) 
A tabela 4 sintetiza os dados de matrícula da RMEl no período desta gestão de 1989 a 1992.

Tabela 4 - Dados de matrícula da RMEI - 1989 a 1992

\begin{tabular}{c|c|c|c|c}
\hline & 1989 & 1990 & 1991 & 1992 \\
\hline Crianças & 2.206 & 2.391 & 2.777 & 3.387 \\
\hline Creches e NEls & 36 & 38 & 42 & 49 \\
\hline
\end{tabular}

Fonte: OSTETTO (2000, p. 105) e FLORIANÓPOLIS (1992, p. 26)

$\mathrm{Na}$ análise da tabela 4, constatamos que 13 novas instituições e 1.181 novas vagas foram criadas nessa gestão, o que totaliza um crescimento de $53,54 \%$. Isto significou que a meta, que estabelecia $12,81 \%$ de crescimento ao ano e que nos quatro anos de gestão somaria $51,24 \%$, foi alcançada e levemente superada (2,30\%).

Conforme Waltrick (2008, p. 102), os atendimentos eram prestados em quatro modalidades: “em creches, em NEls, nas pré-escolas vinculadas às unidades de ensino fundamental e nas creches conveniadas” Todavia, sua análise sinaliza duas estratégias básicas de ampliação: "que a expansão se deu priorizando duas estratégias: a ampliação do atendimento nas pré-escolas vinculadas às escolas de ensino fundamental e a adoção de convênios com entidades comunitárias" (WALTRICK, 2008, p.102).

Sobre o atendimento conveniado, o Relatório de Gestão afirmava que:

a Prefeitura Municipal de Florianópolis, através da Secretaria de Educação, mantém diversos convênios de assistência financeira e/ou pedagógica, junto às entidades comunitárias, destacando-se o Convênio da Merenda Escolar e o de Assistência Financeira. (FLORIANÓPOLIS, 1992, p. 23)

Desse modo, a evolução do atendimento através dos convênios pode ser constatada na tabela 5: 
Tabela 5 - Dados de matrícula da RMEl e dos convênios - 1989 a1992

\begin{tabular}{c|c|c|c}
\hline Ano & RMEI & Convênios & TOTAL \\
\hline 1989 & 2.206 & 1.099 & 3.305 \\
\hline 1990 & 2.391 & 1.318 & 3.709 \\
\hline 1991 & 2.777 & 1.680 & 4.457 \\
\hline 1992 & 3.387 & 2.000 & 5.387 \\
\hline
\end{tabular}

Fonte: FLORIANÓPOLIS (1992)

Numa rápida análise, o atendimento na RMEI cresceu 53,54\%. Já o atendimento realizado pelos convênios teve, nesta mesma gestão, um crescimento da ordem de $81,98 \%$. No ano de 1992 , o atendimento oferecido pela RMEl era de $62,87 \%$, enquanto que o dos convênios respondia por 37,13\% do atendimento total.

Finda a gestão Amin/Bulcão - 1989 a 1992 -, o município de Florianópolis iniciava o período da chamada gestão da Frente Popular.

\section{A gestão popular: zoneamento e ampliação dos convênios com o setor privado-filantrópico}

De 1993 a 1996, o município de Florianópolis foi governado pela coligação da Frente Popular - Sérgio Grando e Afrânio Boppré. Foram amplas as ações deste governo no que diz respeito à Educação no município, com destaque para o Movimento de Reorganização Curricular, que, como sinaliza o Relatório de Gestão 1993-1996, "foi uma ação de democratização desta gestão. A ação por construir a proposta curricular de forma coletiva traduz também, de forma inequívoca, uma opção pelo exercício efetivo da democracia [...]" (FLORIANÓPOLIS, 1996b, p. 20). Em 1994, foi instalado este processo, visando a construir coletivamente a proposta curricular da rede municipal de ensino RME -, da qual foram publicados sete cadernos, resultado de um processo coletivo de discussão:

A proposta curricular publicada nos sete cadernos, em dezembro de 1996, não saiu de um Gabinete, onde uma equipe técnica traçava suas linhas, mas é resultado de um processo coletivo, contínuo, dialético, 
desafiante e enriquecedor, que envolveu a maioria dos trabalhadores da RME, abrangendo também os pais e alunos. (FLORIANÓPOLIS, 1996b, p. 21)

Ainda em 1994, realizou-se pela primeira vez a eleição de diretores em todas as instituições da RME, fato que anteriormente "privilegiava somente as vinte escolas básicas, negando às demais cinquenta e cinco unidades da rede o direito de escolher pelo voto direto e secreto sua direção" (FLORIANÓPOLIS, 1996b, p. 19).

Outra questão é a dos conselhos de escola. A propósito, em 1995 foi lançada a campanha Te assunta, para implantação dos conselhos de escola, aplicando uma lei criada em 1986, mas que nunca fora efetivada na RME. Neste mesmo ano, foram implantados 12 conselhos de escola. A partir de 1995, o Conselho Municipal de Educação "passou a atuar com a delegação de competência concedida pelo Conselho Estadual de Educação" (FLORIANÓPOLIS, 1996b, p. 21).

É interessante destacar que o investimento em Educação ultrapassou os $25 \%$ dos recursos, destinando-se, em 1995, um aporte de "33,15\% do orçamento municipal com Educação. Em todos os anos superamos os 30\%, estando neles incluídas as obras escolhidas pelas comunidades para a educação através do orçamento participativo" (FLORIANÓPOLIS, 1996b, p. 7).

Em 1993, foi realizado um diagnóstico da rede de ensino:

No documento Diretrizes e Metas para a Educação (1993-1996), é ressaltada a existência de "um grave problema" relacionado ao quadro de professores atuantes na rede: mais de 50\% deste é constituído de professores substitutos (p. 24), alertando-se para os problemas que isso acarretava: "instabilidade, não acesso aos benefícios da carreira e a descontinuidade quanto ao trabalho pedagógico propriamente dito". (FLORIANÓPOLIS, 1996a, p. 24)

Também apontou:

[...] uma educação sem projeto político-pedagógico, sem um fio condutor, que desse sentido e possibilitasse uma prática social educativa. Cada unidade funcionava dentro de seu núcleo, pulverizada numa parte, desconectada do todo e sem uma efetiva interação com a comunidade escolar. (FLORIANÓPOLIS, 1996b, p. 5) 
Instalaram-se quatro grandes diretrizes para a Educação no município: “democratização da gestão; democratização do acesso; uma política de educação de jovens e adultos; uma nova qualidade de ensino" (FLORIANÓPOLIS, 1996a, p. 35). Por fim, ciente do preceito constitucional sobre a universalização do ensino de $1^{\mathrm{a}}$ a $8^{\mathrm{a}}$ série, a secretaria passa a admitir entre suas responsabilidades a faixa etária de zero a seis anos:

[...] onde a demanda é muito grande e exige respostas enquanto condição de assegurar o direito de toda criança à educação infantil, assim como contribuir para que as mães trabalhadoras tenham a possibilidade de, via seu trabalho e seu salário, colaborar na busca de melhores condições de vida para suas famílias. (FLORIANÓPOLIS, 1996a, p. 38)

A criança passa a ser tratada como sujeito de direitos, conforme a Constituição de 1988. No entanto:

Para que se possam alcançar estes objetivos, é sabido que [...] as condições básicas para a democratização do acesso e da permanência, que vença a evasão e a repetência, são a garantia de vagas para a matrícula inicial das crianças em idade escolar e/ou daqueles que estão fora da escola, prédios escolares em condições de funcionamento, através de uma política de manutenção, reformas, ampliação e construção da rede física; manutenção dos equipamentos didáticopedagógicos existentes e aquisição de novos. (FLORIANÓPOLIS, 1996a, p. 39)

Até então, democratização de acesso e permanência era obrigatória apenas dos 7 aos 14 anos.

Explorando um pouco mais o Relatório de Gestão 93-96, encontramos, numa de suas metas - garantia do acesso à Educação Infantil -, a adoção do zoneamento, prática empregada pela esfera estadual e que visava à "racionalização do uso dos equipamentos escolares, evitando o excesso de procura de matrícula em algumas escolas e o esvaziamento de outras" (FLORIANÓPOLIS, 1996b, p. 22).

Quanto à expansão do atendimento através dos convênios, registra-se:

[...] passaram de 12 convênios em 1992 para 37 em 1996, fechando o ano com 39 convênios assinados para o ano de 1997. Além do aumento quantitativo, esses convênios passaram por nova formulação que garantiu maior qualidade ao trabalho das conveniadas, ao fornecermos a merenda escolar e contratarmos os professores, de acordo com a política 
educacional da Secretaria para estas áreas. (FLORIANÓPOLIS, 1996b, p. 6)

Se os 12 convênios de 1992, passaram para 37 em 1997, o aumento foi de 208,33\%, o que permite afirmar que esta foi a estratégia de maior expansão de atendimento da Educação Infantil nesta gestão, que ampliou o atendimento também pela construção de duas novas creches - Costa da Lagoa e Chico Mendes.

Para visualizar esse aumento por parte da rede conveniada, os dados foram dispostos na tabela 6 .

Tabela 6 - Dados de matrícula da RMEI e dos convênios - 1992 e 1996

\begin{tabular}{l|c|c|c}
\hline & RME & CONVÊNIOS & TOTAL \\
\hline 1992 & 3.741 & 2.000 & 5.741 \\
\hline 1996 & 4.629 & 4.546 & 9.175 \\
\hline
\end{tabular}

Fonte: FULLGRAF (2001) e FLORIANÓPOLIS (1996)

O ano de 1992 se concluiu atendendo a 3.741 crianças pela RMEI e a 2.000 pela rede conveniada, o que significou $62,87 \%$ de atendimento realizado pela $\mathrm{RMEI}$ e $37,13 \%$ pela rede conveniada. Já no fim desta gestão, os dados informam que $50,45 \%$ dos atendimentos foram realizados pela RMEI e 49,55\% através de convênios, levando a interpretar que o atendimento em Educação Infantil no município era partilhado entre as instituições oficiais e as instituições chamadas "conveniadas".

Nos anos seguintes, o município de Florianópolis experimentou um novo tempo, na gestão do governo Ângela Amin.

\section{A "era Ângela Amin": "uma a mais", grupos de diferentes idades, parcialização do atendimento e vagas ociosas}

Em janeiro de 1997, Ângela Amin assumiu a prefeitura de Florianópolis, à frente da qual permaneceu por dois mandatos consecutivos: de 1997 a 2000 e de 2001 a 2004 . Muitas das conquistas obtidas na gestão da Frente Popular encontravam-se agora 
ameaçadas. Em 2000, a prefeita Ângela Amin não iria realizar a eleição para diretores na RME. Como consequência, foram instaurados 47 processos administrativos disciplinares. Grande foi a mobilização popular e sindical, culminando com a realização do processo eleitoral. A Secretaria Municipal de Educação - SME - exigiu dos candidatos a participação em um curso preparatório para a direção. As eleições, até então realizadas no mês de julho, passaram para o mês de dezembro.

Nesta gestão de 1997 a 2000, as diretrizes da SME foram sintetizadas em “viabilizar condições de exercício pleno da cidadania e criar oportunidades para que todos tenham acesso aos bens historicamente produzidos pelos homens" (FLORIANÓPOLIS, 2000a, p. 7).

Waltrick (2008) afirma que, com tal diretriz, este governo passava a adotar a perspectiva da meritocracia. Os pressupostos dessa visão administrativa se alinham com os princípios da ideologia neoliberal; afinal, consideravam que as oportunidades eram acessíveis a todos e que o êxito ou o fracasso ficavam na dependência do esforço e da capacidade individual. Logo, sob este enfoque, os indivíduos estariam em condições de igualdade, podendo escolher o seu trabalho de acordo com sua formação e interesse. No entanto, vivenciou-se uma profunda desigualdade social.

Dentre as metas propostas, merece menção a da consolidação do currículo para a Educação Básica, incluindo-se Educação Infantil, implementando "uma política permanente de capacitação e aperfeiçoamento dos profissionais da Educação [...] e acompanhamento sistemático a todas as Unidades [...]” (FLORIANÓPOLIS, 2000a, p. 9).

Neste momento, o contexto é pós-LDB 1996 - que, dentre muitas questões, desencadeou a demanda pelo Sistema Municipal de Educação, sua estrutura e funcionamento, apesar de ter sido aprovado somente em 2007. Em 1999, passou a vigorar a primeira Resolução de Educação Infantil. Ainda em 2000, foram apresentados os novos princípios pedagógicos. A intenção:

[...] não é a de apresentar uma nova orientação ou proposta curricular, mas a de estabelecer princípios gerais que levem em conta a experiência já acumulada pelos profissionais que têm atuado diretamente com as 
crianças, de forma a subsidiar a definição ou a consolidação de projetos pedagógicos em cada unidade. (FLORIANÓPOLIS, 2000c, p. 23)

A RME, em consonância com a esfera federal, legitimou as Diretrizes para a Educação Infantil Nacional (1999). Outra novidade aplicada foi a da co-responsabilidade das instituições de Educação Infantil:

[...] as instituições que passam a ser co-responsáveis pela criança nestes novos espaços coletivos necessitam redimensionar suas funções frente a estas mudanças, assumindo uma posição de negação, seja dos projetos de cunho custodial atrelados a perspectivas educacionais higienistas e moralizadoras, seja dos projetos de "preparação para o futuro" que pretendem uma escolarização precoce preocupada com a inserção na escola do Ensino Fundamental. A Educação Infantil tem uma identidade que precisa considerar a criança como sujeito de direitos, oferecendo-lhe condições materiais, pedagógicas, culturais e de saúde para isso, de forma complementar à ação da família. (FLORIANÓPOLIS, 2000c, p. 26)

Desta forma, foi preciso “orientar a ação pedagógica por olhares que contemplem sujeitos múltiplos e diversos, reconhecendo, sobretudo, a infância como "tempo de direitos" (FLORIANÓPOLIS, 2000c, p. 27). O documento Síntese da qualificação da Educação Infantil - 2000 entende a educação das crianças pequenas como responsabilidade coletiva e pública assumida pelo Estado, pela família e a instituição.

Este mesmo documento (FLORIANPOPOLIS, 2000, p. 25) expõe que a Educação Infantil "tem sofrido um mínimo de expansão e, em alguns casos, sofreu até uma diminuição da oferta, em função de não se ter em nenhuma das instâncias governamentais garantia de fontes de financiamento".

Fundamentando sua proposta pedagógica no direito das crianças à educação, sem muitas condições concretas para a efetivação deste direito - falta de financiamento -, por força de determinações legais e com o objetivo de cumprir a legislação, a SME adota a estratégia de "uma vaga a mais". Em sua portaria 017/1999, artigo 5, estabeleceu que "fica assegurada uma vaga a mais, em cada turma, para as crianças encaminhadas pelo Conselho Tutelar, via SME, respeitando o número de crianças por turma conforme o art. 4". 
De acordo com Fullgraf (2001), esta "vaga a mais" foi um acordo realizado entre a SME e o Conselho Tutelar, como consta de um dos relatos da entrevista com uma técnica da secretaria:

É uma negociação entre o Conselho Tutelar e a Secretaria da Educação. As mães que não têm condições e estão numa situação caótica, nível de miserabilidade total e que precisam, então pedem para ir direto para o Conselho, para o Conselho mandar um parecer para ela, para ela vir trazer um encaminhamento do Conselho. Tem que ter um encaminhamento do Conselho; então foi uma negociação feita com o Conselho e com a Secretaria. Essa mãe tem que ir para o conselho para conseguir um encaminhamento, então vir aqui. Trazer para cá, para a gente conseguir negociar com a creche. (FULLGRAF, 2001, p. 120)

Ainda em Fullgraf (2001) encontramos o pronunciamento da Promotoria de Infância com relação a esta "vaga a mais":

[...] Não existe vaga do Conselho, nem pode a criança ser distinguida como vaga do Conselho Tutelar, porque isso é um absurdo, você discriminar e outra, limitar a atuação do Conselho Tutelar, como se o Conselho Tutelar fosse um órgão político que, para fazer uma média, a Secretaria coloca lá que uma criança vai ser assegurada por sala, quando na verdade, isso discrimina... Se elas entram lá e são mencionadas como vindas do Conselho Tutelar, o que vai acontecer é uma discriminação e isso não pode ocorrer [...] (FULGRAF, 2001, p. 120, 121)

A tabela 7 possibilita uma melhor visualização do aumento das matrículas na RMEI e na rede conveniada.

Tabela 7 - Dados de matrícula da RMEl e dos convênios - 1997 a 2000

\begin{tabular}{l|c|c|c}
\hline & RMEI & CONVÊNIOS & TOTAL \\
\hline 1997 & 4.820 & 5.082 & 9.902 \\
\hline 1998 & 4.959 & 5.918 & 10.877 \\
\hline 1999 & 5.360 & 6.311 & 11.671 \\
\hline 2000 & 5.536 & 6.331 & 11.867 \\
\hline
\end{tabular}

Fonte: FULLGRAF (2001, p. 84)

Uma análise atenta da tabela mostra que no ano de 1997 o atendimento ofertado pela RMEI correspondia a 48,68\%, enquanto que o atendimento realizado pela rede 
conveniada era de 51,32\%. Já no fim desta primeira gestão, no ano de 2000, tem-se a seguinte relação: 46,65 \% ofertado pela RMEl e 53,35\% pela rede conveniada, ou seja, é mais uma gestão que vai investindo nos convênios com organizações privadas, passandoIhes a responsabilidade por mais da metade deste atendimento. Considerando-se que nesta primeira gestão foram criadas 1.965 vagas, das quais 716 pela RMEI e 1.249 pela rede conveniada, conclui-se que a RMEl ampliou em $36,44 \%$ as novas vagas, enquanto que o crescimento por parte da rede conveniada foi de $63,56 \%$, comprovando, através dos dados, que a ampliação das vagas na Educação Infantil mais uma vez se apoiou na rede conveniada. O gráfico 1 ilustra os atendimentos públicos e conveniados entre os anos de 1996 e 2000.

Gráfico 1 - Atendimento Público e Conveniado (1996 a 2000)

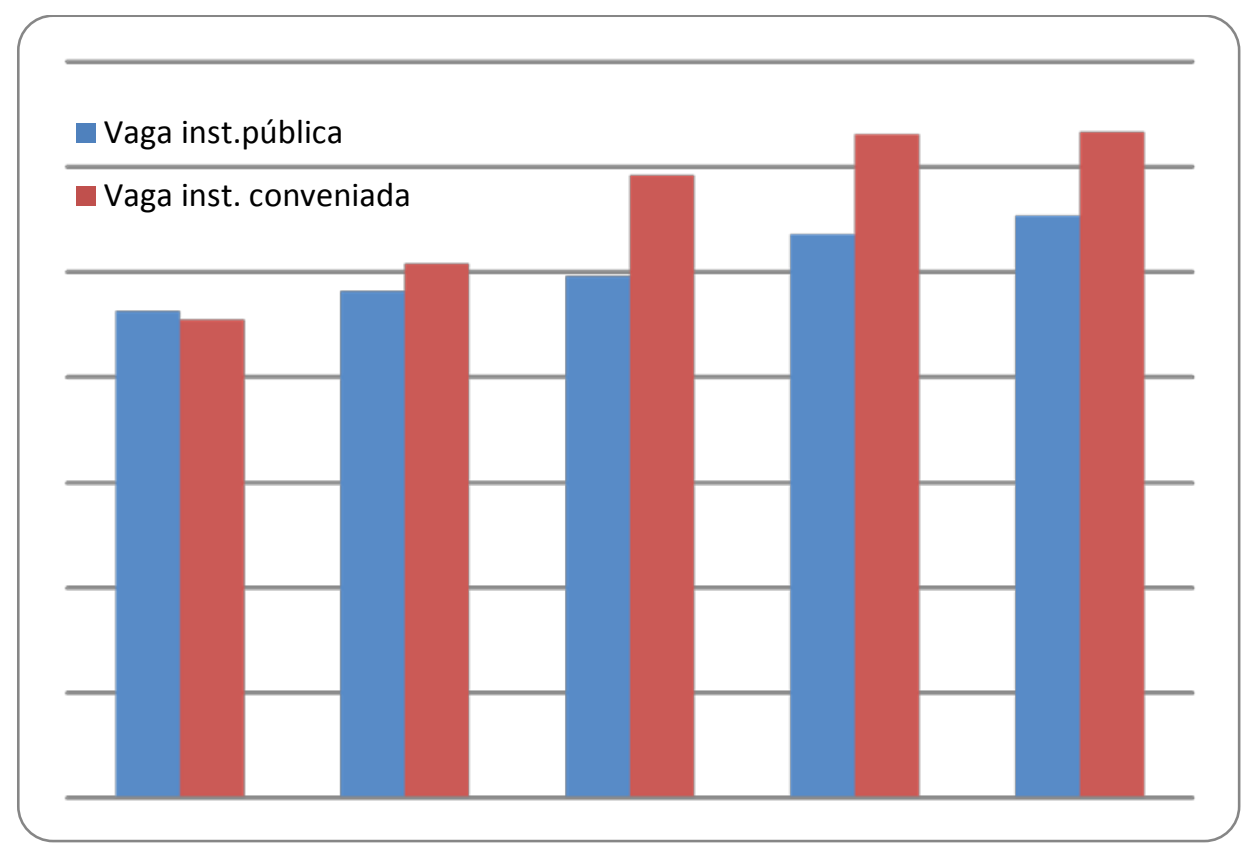

Fonte: OESTREICH (2011, p.131).

O gráfico de fato confirma que, de 1997 até 2000, boa parte do atendimento das crianças no município era realizada em intuições conveniadas.

Ao fim de sua primeira gestão, na tentativa de minimizar a falta de vagas, a SME lançou mão de outra estratégia - turmas com crianças de diferentes idades -, através da Portaria $n^{\circ}$ 036/2000, relativa a ingresso na rede municipal de Florianópolis, de acordo 
com o estabelecido no Parágrafo Único do artigo 6: "conforme Proposta Pedagógica da Unidade, poderão ser organizadas turmas com crianças de diferentes idades, respeitando o número maior de crianças".

Na segunda gestão da prefeita Ângela Amin, encontramos na Portaria 037/2001 a primeira referência à reserva de vagas para crianças em risco social. Em 2002, houve uma alteração na estrutura da SME - Lei n 105/2002 -, que também afetava a resolução de Educação Infantil. Houve uma mudança na nomenclatura e as turmas passaram a ser definidas como "grupos".

Em 2004, devido novamente à demanda crescente da Educação Infantil, surgiu nova estratégia: redução da jornada de atendimento das crianças. Conforme estabelecia a Portaria nº32/2003, em seu Art. 6:

Fica estabelecido que, das novas vagas oferecidas nas Unidades de Educação Infantil que têm atendimento em período integral para o ano de 2004, 60\% (sessenta por cento) das vagas serão para atendimento em período parcial (das $07 \mathrm{~h}$ às $13 \mathrm{~h}$ ou das $13 \mathrm{~h}$ às $19 \mathrm{~h}$ ). As crianças que já têm atendimento em período parcial nas Unidades de Educação Infantil, que atendem integralmente, poderão concorrer a uma vaga de período integral no percentual de 40\% (quarenta por cento) acima referido. (FLORIANÓPOLIS, 1999/2010)

Assim, das crianças que procuravam por novas vagas, $60 \%$ seriam atendidas em atendimento parcial e 40\%, em atendimento integral.

Ainda em 2004, uma instrução normativa - 001/2004 - tratou de organizar o preenchimento das vagas ociosas que se encontravam na RMEI.

Os dados referentes à segunda gestão do governo Ângela Amin estão sintetizados na tabela 8. 
Tabela 8 - Dados de matrícula da RMEl e dos convênios - 2001 a 2004

\begin{tabular}{c|c|c}
\hline & RMEI & Convênios \\
\hline 2001 & 6.102 & Sem dados \\
\hline 2002 & 6.669 & Sem dados \\
\hline 2003 & 6.930 & Sem dados \\
\hline 2004 & 7.522 & Sem dados \\
\hline
\end{tabular}

Fonte: SME (2011)

Em sua segunda gestão - 2001 a 2004 -, foram criadas 1.420 vagas na RMEl; no entanto, não foi possível uma análise mais aprofundada, pois não foram localizados os dados da rede conveniada. Já na primeira gestão de seu governo, foram criadas 1.965 vagas; isto representa uma diferença de 545 vagas a menos na segunda gestão do que na primeira.

Por fim, concluímos que o governo de Ângela Amin, em suas duas gestões, aplicou as seguintes estratégias de ampliação: uma vaga a mais - Conselho Tutelar; ampliação dos convênios - visualizados somente na primeira gestão; turmas de diferentes idades; parcialização da jornada de atendimento das crianças e preenchimento de vagas ociosas.

Novas eleições foram realizadas. A gestão que assume é a do governo Dário Berger.

\section{"Era Berger": "creches ampliadas”, municipalizações, dentre outras}

Em 2005, assume Dário Berger, reeleito em 2008. Uma das políticas da SME prevê a "ampliação e qualificação do atendimento da Educação Infantil [...]" (FLORIANÓPOLIS, 2008a, p. 6). Com relação ao Departamento de Educação Infantil (DEI), seu comprometimento "é com a expansão e melhoria da qualidade no atendimento às crianças de o a 6 anos, pautado pela indissociabilidade entre o cuidar/educar" (FLORIANÓPOLIS, 2008a, p. 16).

Em uma de suas diretrizes, o Projeto Político Pedagógico 2006/2008 se propõe garantir a "organização dos tempos, dos espaços e dos materiais que possibilitem o 
brincar e as interações, através da convivência coletiva e das múltiplas linguagens, de modo que a criança viva plenamente sua infância" (FLORIANÓPOLIS, 2008a, p. 16).

A gestão democrática atrela a garantia do processo de ensino e aprendizagem com destaque na qualidade, modernizando a administração, "com ênfase nas pessoas" (FLORIANÓPOLIS, 2008a, p. 25):

Deste modo, a construção, a reforma e a ampliação das UEs, a aquisição de materiais e equipamentos e a adoção de procedimentos informatizados e em rede são metas prioritárias desta gestão, contribuindo, assim, para se atingir as diretrizes propostas e alcançar a sustentabilidade da educação, com qualidade, eficiência e rapidez. (FLORIANÓPOLIS, 2008a, p. 25)

Outro aspecto diz respeito ao investimento na Educação: em 2005 investiu-se 31\% do orçamento próprio do município:

A necessidade de ampliação e melhoria da rede implica obter novas fontes de recursos financeiros, sob pena de inviabilizar o atendimento das necessidades educacionais do Município. É indispensável que os poderes públicos - federal e estadual - ampliem a sua participação no financiamento da educação, principalmente para a Educação Infantil. A criação do FUNDEB contribuirá para esta finalidade somente se houver esta ampliação de recursos e a justa definição do custo educando da Educação Infantil. (FLORIANÓPOLIS, 2008a, p. 25)

No ano de 2006, de acordo com o documento "Tiro De Meta - Segundo Tempo 2005/2008" (p. 16), havia 37 creches e 30 NEIs. Neste mesmo documento, consta, na meta 19, "ampliar o atendimento das crianças de o a 6 anos em instituições educativas da RME", e uma de suas ações consiste em "redimensionar os agrupamentos das crianças (organizar junto às unidades educativas agrupamentos de diferentes idades)" (FLORIANÓPOLIS, 2008b, p. 34), evidenciando-se como uma das estratégias utilizadas por esta gestão para expandir o atendimento da Educação Infantil. A outra ação trata da "ampliação e construção de creches e NEIs respeitando a demanda da comunidade" (FLORIANÓPOLIS, 2008b, p. 34). Entenda-se por “ampliação" o aumento da área construída, com construção/anexação de mais salas de atividades nos prédio das 
instituições já existentes e onde o espaço físico permitisse. A isto chamaremos de "creche ampliada".

Em setembro de 2007, foi celebrada a assinatura do primeiro Termo de Ajuste de Conduta - TAC -, pelo qual o município deveria "criar 2.448 novas vagas para o atendimento da demanda da Educação Infantil, sendo 1.940 novas vagas e inclusão de 508 crianças em vagas ociosas" (FLORIANÓPOLIS, 2009, p.16). Neste mesmo ano, foram atendidas 8.320 crianças e, em 2009, 10.263 crianças, significando 1.943 novas vagas.

Com relação às vagas ociosas, as 508 de 2007 caíram para 269 em 2009, o que significou a ocupação de 239 vagas ociosas. O não preenchimento das demais se deveu basicamente ao fato de "estarem em comunidades que não têm demanda e outras por não haver interesse da comunidade pelo grupo de atendimento ou pelo período (a maioria das vagas é no período matutino)" (FLORIANÓPOLIS, 2009, p. 16).

A tabela 9 apresenta os dados referentes às matrículas da RMEI e da rede conveniada na primeira gestão do governo Dário Berger.

Tabela 9 - Dados de matrícula da RMEl e dos convênios - 2005 a 2008

\begin{tabular}{c|c|c|c}
\hline & RME & Convênios & TOTAL \\
\hline 2005 & 7.574 & 2.978 & 10.552 \\
\hline 2006 & 7.687 & 3.370 & 11.057 \\
\hline 2007 & 8.198 & 3.119 & 11.317 \\
\hline 2008 & 8.537 & 2.324 & 10.861 \\
\hline
\end{tabular}

Fonte: SME (2011)

Verifica-se um crescimento real de apenas 309 novas vagas de 2005 a 2008, ocorrendo um significativo decréscimo no atendimento realizado pela rede conveniada. No início de sua gestão, em 2005, 71,28\% dos atendimentos eram realizados pela RMEI e $28,22 \%$, pela rede conveniada; já ao final da primeira gestão, contabilizou-se $78,60 \%$ do atendimento sob a responsabilidade da RMEI enquanto que $21,40 \%$ continuou sob a responsabilidade da rede conveniada. 
Já na segunda gestão, ao explorar os documentos a partir do ano de 2009, constatamos que na meta 4 - ampliação do atendimento na Educação Infantil - sua intenção foi "redimensionar alguns agrupamentos para o preenchimento das vagas" (FLORIANÓPOLIS, 2009, p. 15). Assim, “dos 530 grupos de Educação Infantil, 114 foram agrupados com crianças de diferentes idades para o preenchimento de vagas em aberto" (FLORIANÓPOLIS, 2009, p. 15); logo, 21,51\% dos grupos atendidos na RMEI representam agrupamentos - por idade aproximada.

Outro dado importante refere-se à extinção de alguns convênios: “Foi encerrado o atendimento nos 7 NACs (Núcleos de Atendimento a Crianças - creches domiciliares) existentes em dezembro de 2009 e para 2010 essas crianças serão atendidas nas Creches Conveniadas ou Municipais" (FLORIANÓPOLIS, 2009, p. 15). Assim, com o encerramento de alguns convênios, estas crianças "migraram” também para as instituições da RMEl.

Ainda segundo o Relatório de Gestão, 2009 (FLORIANÓPOLIS, 2009, p. 3), contabilizam-se 48 creches e $30 \mathrm{NEIs,} \mathrm{perfazendo} \mathrm{um} \mathrm{aumento} \mathrm{de} 11$ creches em três anos de gestão.

Com relação à expansão do atendimento, algumas instituições foram construídas com recursos federais - MEC. São elas: Creche Julia Maria Rodrigues; NEI Dra . Zilda Arns Neumann; Creche Lausimar Maria Laus, totalizando 470 crianças atendidas. No final de 2011, foi inaugurada a Creche Poeta Cruz e Sousa, e ainda está prevista a Creche Canasvieiras. Além disto, em 2009 foram municipalizadas cinco creches, que antes pertenciam à rede estadual - Creche Anjo da Guarda, Creche Bem-te-vi, Creche Cristo Redentor, Creche Nossa Senhora de Lourdes, Creche Machado de Assis -, totalizando, em agosto de 2011, 597 crianças atendidas. Também foram municipalizadas algumas creches conveniadas - Creche Altino Dealtino de Cabral, Creche Elisabete Nunes Anderle, Creche Franklin Cascaes, Creche Irmã Scheila -, totalizando 261 crianças atendidas, além de outras instituições que não se enquadram nessa apresentação, como, por exemplo, a recente inauguração da Creche Carlos Humberto Pederneiras Corrêa, na Vila Santa Rosa, Agronômica, com capacidade para 60 crianças em período integral. Todos estes dados se referem ao mês de agosto de 2011. 
Uma das principais estratégias é a da ampliação das creches que dispunham de espaço físico para a construção de mais salas de atividades, anexadas ao prédio já existente, de modo a atingir um padrão que propunha que cada unidade possuísse dez salas ou mais.

Em 2006, começaram a ser inauguradas as primeiras "creches ampliadas". Considerando-se os anos de 2006 a 2011 (agosto), encontramos 12 instituições que se enquadram nessa denominação: Creche Almirante Lucas Boiteux (2006), Creche Caetana Marcelina Dias (2006), Creche Firmino Francisco Vieira (2006), Creche Ingleses (2006), Creche Orlandina Cordeiro (2006), Creche Doralice Teodora Bastos (2007), Creche Waldemar da Silva Filho (2007), NEI Armação (2008), NEI Ingleses (2008), NEI São João Batista (2009), Creche Anna Spyrios (2009), Creche Celso Pamplona (2010).

Em síntese, a estratégia de "creche ampliada" apresentou a seguinte evolução no atendimento das matrículas na RMEl:

Tabela 10 - Aumento das vagas por ano, na estratégia de “creche ampliada”

\begin{tabular}{c|c|c}
\hline ANO & $\begin{array}{c}\text { NÚMERO DE } \\
\text { VAGAS }\end{array}$ & PERCENTUAL \\
\hline 2006 & 357 & $27,38 \%$ \\
\hline 2007 & 145 & $31,12 \%$ \\
\hline 2008 & 462 & $17,41 \%$ \\
\hline 2009 & 227 & $08,66 \%$ \\
\hline 2010 & 113 & $100 \%$ \\
\hline TOTAL & 1.304 & \\
\hline
\end{tabular}

Fonte: OESTREICH (2011, p. 140)

Conforme a tabela 10, em 2006, foram criadas 357 vagas, o que correspondeu a 27,38\% de aumento em seu número. Em continuidade, no ano de 2007 foram abertas 145 vagas, perfazendo $11,12 \%$ de expansão do atendimento. O grande salto foi registrado no ano de 2008 , com $35,43 \%$ de expansão do atendimento, totalizando 462 vagas. Este fato se explica pelas ampliações nos NEls de Ingleses e Armação, que eram instituições de atendimento parcial. Note-se que somente o NEI Ingleses apresentou 314 novas vagas. 
Segundo Oestreich (2011), o NEI Ingleses, que antes atendia a 106 crianças, em 2008 passou a atender a 420 crianças; o NEl Armação, que atendia a 159 crianças, em 2008 passou a atender a 307 crianças. Por fim, em 2009, verificamos a criação de 227 vagas e, em 2010, mais 113 vagas, representando um crescimento de $17,41 \%$ e 8,66\%, respectivamente, na expansão do atendimento.

De modo geral, todavia, se considerarmos os dados de matrícula dos anos de 2000 e de 2010, somando-os aos do atendimento da RMEI e dos convênios, verifica-se um aumento real de 712 novas vagas em uma década. Por outro lado, evidencia-se a "migração" das crianças de zero a cinco anos para a responsabilidade do município. Se, em 2000, $47 \%$ do atendimento era realizado pela RMEl e 53\% pela rede conveniada, este panorama se modifica em muito, pois, em 2010, 83\% das crianças são atendidas pela RMEI e apenas $17 \%$ pela rede conveniada, conforme visualizado na tabela 11 , a seguir.

Tabela 11 - Dados de matrícula do RMEl e dos convênios - 2000 e 2010

\begin{tabular}{c|c|c|c}
\hline & RMEI & CONVENIOS & TOTAL \\
\hline 2000 & 5.536 & 6.331 & 11.867 \\
\hline 2010 & 10.439 & 2.140 & 12.579 \\
\hline
\end{tabular}

Fonte: OESTREICH (2011, p. 137)

\section{Considerações finais}

Identificamos os processos de expansão de atendimento da RMEI desde a sua criação (1976), mapeando as estratégias adotadas pelos governos municipais e a dinâmica impressa no funcionamento da RMEl. Isto nos permitiu constatar que a implantação dos primeiros NEls ocorreu sob a lógica da expansão a baixo custo.

A primeira “onda expansionista” no município aconteceu no período de 1980 a 1983, com um aumento de vagas correspondente a 204,15\%, exclusivamente, nestes três anos. 
Na sequência desta "onda expansionista" - 1986 a 1988 -, a tentativa foi de ampliar a concepção de educação das crianças, buscando um caráter mais educativo, embora não escolarizante. Já nos anos de 1989 a 1992, após a promulgação da Constituição Federal de 1988, que garantiu à criança de zero a seis anos o direito à Educação, observamos uma nova "onda de expansão" na pré-escola. Em 1992, a rede conveniada contava com 12 instituições privadas sem fins lucrativos; em 1997, esse número subiu para 37 instituições. Isto significou um aumento de 208,33\% nestes convênios, o que nos permite afirmar que a “onda de expansão" se deveu à estratégia dos convênios. A gestão da Frente Popular, por sua vez, se distinguiu pela estratégia do zoneamento e dos convênios.

A partir de 1999, já na gestão de Ângela Amim, identificamos novas estratégias para fomentar a expansão o atendimento na RMEl: uma vaga "a mais" - um acordo com o Conselho Tutelar, composição de turmas com crianças de diferentes idades, parcialização do atendimento e preenchimento das vagas ociosas.

Na sequência, percorrendo a gestão do governo Berger, encontramos a estratégia de maior impacto na expansão do atendimento, que nomeamos de "creches ampliadas". Encerraram-se também os convênios com os NACs - antigas creches domiciliares -, transferindo-se as crianças para instituições da rede pública, ou conveniada, além da municipalização de creches oriundas da esfera estadual. Somam-se, ainda, as construções realizadas pelo MEC.

Em 2009, foram alcançadas mais de 12 mil matrículas. Portanto, por iniciativa da municipalidade, seja por incorporação das matrículas da rede estadual, seja por convênio com algumas das instituições, ampliou-se o atendimento da RMEI, conforme indica a pesquisa sobre a qualidade da Educação Infantil realizada pela Fundação Carlos Chagas em 2010, que incluiu Florianópolis em seu levantamento (CAMPOS, 2010, p. 347).

Vale ainda relembrar que a expansão do atendimento também foi induzida pelo Termo de Ajustamento de Conduta firmado com o Ministério Público em 2007.

Com relação à expansão do atendimento, recorremos a Azanha (2004), que chama a atenção no sentido de que a expansão do direito à Educação não pode ser barrada tão 
somente por argumentos de ordem pedagógica. Afinal, não se trata tão somente de uma questão pedagógica; ela é também uma questão política, pois somente "a superação de preconceitos técnicos permite situar a maciça ampliação de oportunidades na sua autêntica dimensão, que é política" (AZANHA, 2004, p. 339).

A discussão acerca da democratização da educação sempre foi permeada por tensões - passadas e presentes -, que têm subordinado o fator quantidade à dimensão política e o da qualidade, ao preceito constitucional do Direito; neste caso, da criança de zero a seis anos.

Superar a histórica dicotomia entre quantidade e qualidade continua sendo o grande desafio para a educação brasileira.

\section{Referências}

AZANHA, José Mário Pires. Democratização do ensino: vicissitudes da idéia no ensino paulista. In: Educação e Pesquisa. São Paulo, v. 30, n. 2, maio./ago. 2004. p. 335-344.

BRASIL. Constituição (1988). Constituição da República Federal do Brasil: promulgada em 5 de outubro de 1988. Brasília, DF: Imprensa Oficial, 1988.

BRASIL. Lei n. ${ }^{\circ}$ 9.394, de 20 de dezembro de 1996. Lei de diretrizes e bases da Educação: estabelece as diretrizes e bases da educação nacional. 1996. Brasília, DF: Imprensa Oficial, 1996.

BRASIL. Resolução CNE/CEB nº1/1999, de 7 de abril de 1999. Institui as Diretrizes Curriculares Nacionais para a Educação Infantil. Brasília, DF: Imprensa Oficial, 1999.

CAMPOS, Maria. Malta. Educação Infantil no Brasil - avaliação qualitativa e quantitativa. Relatório Final. São Paulo: FCC, 2010.

FLORIANÓPOLIS. Secretaria Municipal de Educação, Saúde e Assistência Social. Plano de educação: 1980-1983. Florianópolis, 1983. 
FLORIANÓPOLIS. Secretaria Municipal de Educação. Plano de ação: triênio 86-88. Florianópolis, 1986.

FLORIANÓPOLIS. Secretaria Municipal de Educação. Relatório de desenvolvimento da política educacional no município de Florianópolis: período 1986-1988. Florianópolis, maio 1988.

FLORIANÓPOLIS. Secretaria Municipal de Educação. Relatório de Gestão 1989-1992. Florianópolis, 1992.

FLORIANÓPOLIS. Secretaria Municipal de Educação. Traduzindo em ações: das diretrizes a uma proposta curricular na Educação Infantil. Florianópolis, 1996a.

FLORIANÓPOLIS. Secretaria Municipal de Educação. Relatório gestão 93/96: um projeto político pedagógico traduzido em ações. Florianópolis, $1996 \mathrm{~b}$.

FLORIANÓPOLIS. Secretaria Municipal de Educação. Projeto POLÍTICO PEDAGÓGICO. Nei Armação. Florianópolis, 2000a.

FLORIANÓPOLIS. Secretaria Municipal de Educação. Síntese da qualificação da Educação Infantil. Florianópolis, 200ob.

FLORIANÓPOLIS. Secretaria Municipal de Educação. Subsídios para reorganização didática da Educação Básica do Município. Florianópolis, 2000c.

FLORIANÓPOLIS. Secretaria Municipal de Educação. Projeto Político Pedagógico. Florianópolis, 2008a.

FLORIANÓPOLIS. Secretaria Municipal de Educação. Tiro de meta - segundo tempo. Florianópolis, 2008b.

FLORIANÓPOLIS. Secretaria Municipal de Educação. Relatório de gestão. Florianópolis, 2009.

FÜLGRAF, Jodete Bayer Gomes. A Infância de papel e o papel da infância. Dissertação (mestrado) - Universidade Federal de Santa Catarina, Mestrado em Educação, Florianópolis, 2001.

OESTREICH, Marlise. Democratização da educação infantil no município de Florianópolis: uma analise das "creches ampliadas". Dissertação (mestrado) - Universidade Federal de Santa Catarina, Mestrado em Educação, Florianópolis, 2011. 
OSTETTO, Luciana Esmeralda. Educação infantil em Florianópolis. Florianópolis: Cidade Futura, 2000.

WALTRICK, Rose Elaine de Liz. O coordenador pedagógico na educação infantil na rede municipal de educação de Florianópolis: marcas de uma experiência democrática. Dissertação (mestrado) - Universidade Federal de Santa Catarina, Mestrado em Educação, Florianópolis, 2008.

Recebido em: 19/11/2012 Aprovado em: 08/04/2013

Universidade do Estado de Santa Catarina - UDESC Programa de Pós-Graduação em Educação - PPGE Revista Linhas Volume 15 - Número 28 - Ano 2014 revistalinhas@gmail.com 